\title{
Kepuasan Masyarakat Terhadap Pelayanan Rumah Sakit Rujukan di Provinsi Kepulauan Riau Tahun 2019
}

\author{
Kiki Rizki Dasaryandia, Yulastri Arif ${ }^{\text {b }}$, Eka Roza Wijaya ${ }^{c}$ \\ ${ }^{a}$ Magister Keperawatan Fakultas Keperawatan, Universitas Andalas, Padang, 25163, Indonesia \\ ${ }^{\mathrm{b}}$ Fakultas Keperawatan, Universitas Andalas, Padang, 25163, Indonesia \\ ${ }^{c}$ Dinas Kesehatan Kota Batam, Kepulauan Riau, 29444, Indonesia \\ e-mail korespondensi: kiki.rizki1991@gmail.com
}

\begin{abstract}
Patient satisfaction is one indicator of the quality of health services. However, it needs to be recognized that patient expectations have not been fulfilled by health services, this is reflected in the still low level of patient satisfaction in various health service centers. The purpose of this study was to analyze and compare patient satisfaction in three government hospitals in Batam City. The government hospitals are Rumah Sakit Umum Pusat (RSUP), Rumah Sakit Umum Daerah (RSUD), and RSBP. This research is a quantitative research with descriptive analytic design and cross sectional approach. The study population was patients who visited all three hospitals with a total sample of 762 people taken by accidental sampling technique. The data was taken using a questionnaire issued by the Ministry of Defense of the Republic of Indonesia regarding the Community Satisfaction Index (IKM) on hospital services. This research was conducted for 3 months starting from April to June 2019. The dependent variable of the study was Patient Satisfaction measured using SMIs and the independent variable was service performance in three Riau Islands referral hospitals. The results showed that the RSUD and RSUP had a good service performance assessment, while the RSBP service performance was judged to be poor. However, the satisfaction of patients assessed through IKM in RSBP is the highest compared to the other two hospitals. This study shows the low performance value of RSBP services is not in line with the high IKM value. This can be caused even though they do not have good service performance, but because RSBP is the last reference, which makes them have no choice but to be satisfied with the existing conditions. Nevertheless, it is hoped that hospitals can improve the performance of service providers so that they can satisfy patients as service users.
\end{abstract}

Keywords: Quality of Service, Service Elements, Satisfaction Index.

\begin{abstract}
Abstrak
Kepuasan pasien merupakan salah satu indikator dari kualitas pelayanan kesehatan. Namun perlu diakui ternyata harapan pasien belum terpenuhi oleh pelayanan kesehatan, hal ini tercermin dari masih rendahnya kepuasan pasien di berbagai pusat pelayanan kesehatan. Tujuan penelitian ini adalah menganalisis dan membandingkan kepuasan pasien di tiga rumah sakit pemerintah di Kota Batam. Adapun rumah sakit pemerintah tersebut adalah: Rumah Sakit Umum Pusat (RSUP), Rumah Sakit Umum Daerah (RSUD), dan RSBP (Rumah Sakit Swasta). Penelitian ini merupakan penelitian kuantitatif dengan desain deskriptif analitik dan pendekatan cross sectional. Populasi penelitian yaitu pasien yang berkunjung ke ketiga rumah sakit dengan jumlah sampel 762 orang yang diambil dengan teknik accidental sampling. Data diambil dengan menggunakan kuisioner yang dikeluarkan oleh KEMENPAN RI tentang Indeks Kepuasan Masyarakat (IKM) terhadap pelayanan rumah sakit. Penelitian ini dilakukan selama 3 bulan mulai dari April s.d. Juni 2019. Variabel dependen penelitian adalah Kepuasan Pasien yang diukur menggunakan IKM dan variabel independen adalah kinerja pelayanan di tiga rumah sakit rujukan Kepulauan Riau. Hasil penelitian menunjukkan bahwa RSUD dan RSUP memiliki penilaian kinerja pelayanan baik, sementara kinerja pelayanan RSBP dinilai kurang baik. Namun, kepuasan pasien yang dinilai melalui IKM di RSBP justru paling tinggi dibandingkan dua RS lainnya. Penelitian ini menunjukkan nilai kinerja pelayanan RSBP yang rendah tidak sejalan dengan nilai IKM yang tinggi. Hal ini dapat disebabkan karena meskipun tidak mempunyai kinerja pelayanan yang baik, akan tetapi karena RSBP merupakan rujukan terakhir, yang membuat mereka tidak memiliki pilihan selain harus puas dengan kondisi yang ada. Walaupun demikian, diharapkan rumah sakit dapat meningkatkan kinerja pemberi layanan sehingga dapat memuaskan pasien sebagai pengguna layanan.
\end{abstract}

Kata kunci: Kualitas pelayanan, elemen pelayanan, indeks kepuasan. 


\section{PENDAHULUAN}

Undang undang dasar (UUD, 1945) pasal 27 ayat kedua menyatakan negara menjamin kesehatan setiap warga negara, artinya semua warga negara tanpa kecuali mempunyai hak yang sama dalam penghidupan materi seperti kesehatan. Kesehatan merupakan investasi karena menjadi modal dasar bagi segenap masyarakat dalam beraktivitas dan menjalankan kehidupannya. Untuk itu, pusat pelayanan kesehatan masyarakat atau rumah sakit memiliki peran penting dalam menjaga kesehatan warga negara indonesia. Namun faktanya keluhan masyarakat terhadap kualitas pelayanan rumah sakit sebagai layanan publik masih tinggi sehingga pemerintah harus menyediakan pelayanan kesehatan yang memadai dan dapat diakses dengan mudah oleh masyarakat umum.

Menurut hasil survei governance and decentralization di 20 provinsi di Indonesia, kinerja pelayanan publik masih jauh dari prinsip tata pemerintahan yang baik (Dwiyanto, 2003). Selain itu, laporan dari World Competitiveness Ranking (2018) menyatakan kinerja pelayanan publik di Indonesia memiliki indeks competitiveness rendah diantara 100 negara paling kompetitif di dunia (Cullen \& Cushman, dalam Dwiyanto, 2003). Sementara, kondisi masyarakat semakin kritis, berani, dan semakin sadar akan apa yang menjadi hak dan kewajibannya, yang kemudian secara tidak langsung memaksa pelayanan publik, termasuk pelayanan rumah sakit harus berorientasi pada kepuasaan masyarakat, jika tidak maka rumah sakit akan ditinggalkan dan diganti dengan pelayanan rumah sakit swasta yang lebih menjanjikan.

Kepuasaan pasien merupakan salah satu indikator pelayanan kesehatan yang bermutu. Menurut Pohan (2007) kepuasan pasien adalah tingkat perasaan pasien yang timbul sebagai akibat dari kinerja layanan kesehatan yang diperolehnya, setelah pasien membandingkan dengan apa yang diharapkannya. Pendapat lain dari Kotler (2008), kepuasan pasien adalah perasaan senang seseorang yang timbul karena hasil yang pasien dapatkan sesuai dengan yang pasien harapkan.

Tingkat kepuasaan pasien terhadap pelayanan kesehatan di beberapa negara masih rendah, termasuk di Indonesia. Menurut Ndambuki (2013), tingkat kepuasaan pasien di Kenya hanya 40,4\%, kepuasan pasien di Bakhtapur India lebih rendah yaitu $34.4 \%$ (singh, kaur, \& rochwani, 2013). Sedangkan tingkat kepuasaan pasien di beberapa kota Indonesia menunjukkan angka kepuasaan pasien yang juga rendah seperti angka kepuasan di rumah sakit Maluku Tengah 42,8\% dan di rumah sakit Islam Bukit Tinggi Sumatra Barat 44,4\% (Latupono, A., M. M. Alimin, 2015).

Kepuasan pasien di puskesmas Batu Retno Wonogiri sedikit lebih tinggi dibandingkan di rumah sakit Maluku Tengah dan Sumatera Barat yaitu $72.58 \%$. (Handayani, 2016).

Adapun penilaian kepuasan pasien menurut MENPAN no 14 tahun 2017 meliputi 11 unsur pelayanan yaitu : Kemudahan prosedur pelayanan, kemudahan persyaratan, kejelasan dan kepastian petugas, kedisiplinan petugas, tanggung jawab petugas, kemampuan petugas, kecepatan, keadilan, kesopanan dan keramahan petugas, kewajaran biaya, kejelasan rincian biaya, ketepatan pelaksanaan jadwal waktu, kenyamanan dan keamanan.

Kepulauan Riau memiliki 27 rumah sakit pemerintah dan swasta, 3 diantaranya rumah sakit rujukan yaitu RSUP, RSUD, dan RSBP. Jumlah kunjungan pasien yang berkunjung ke RSUD berjumlah 181,409 yang tediri dari kunjungan rawat jalan 167,481 pasien dan rawat inap 13,928 pasien. Kunjungan RSUP berjumlah 107.460 pasien yang tediri dari kunjungan rawat jalan 98,662 
pasien dan rawat inap 8,798 pasien. Sementara, kunjungan RSBP berjumlah 121.981 pasien yang tediri dari kunjungan rawat jalan 113,572 pasien dan rawat inap 8,409 pasien. Berdasarkan studi awal ke tiga rumah sakit rujukan di provinsi kepulauan Riau didapatkan hasil survey internal terhadap IKM di tiap- tiap rumah sakit dalam kategori baik.

Tujuan penelitian ini adalah menganalisis dan membandingkan kepuasan pasien terhadap pelayanan kesehatan di tiga rumah sakit rujukan di Provinsi Kepri.

\section{METODE}

Jenis penelitian ini adalah kuantitatif dengan desain penelitian deskriptif analitik dan menggunakan pendekatan cross sectional. Populasi dalam penelitian ini adalah seluruh pasien yang berkunjung ke tiga rumah sakit pemerintah di Kepulauan Riau. Sampel diambil dengan menggunakan teknik accidental sampling yaitu pasien yang datang ke rumah sakit rujukan di provinsi Kepulauan Riau yang diambil secara proposional, di RSUP berjumlah 329 sampel, RSUD berjumlah 214 sampel, dan RSBP berjumlah 219 sampel, maka total keseluruhan sampel dalam penelitian ini berjumlah 762 sampel.

Adapun kriteria inklusi dalam penelitian ini adalah pasien yang dirawat lebih 2 hari, dan pasien yang bersedia jadi respoden. Adapun kriteria eksklusi adalah pasien anak - anak, pasien yang di rawat ICU, pasien buta huruf, dan pasien tidak sadar.

\section{HASIL}

Secara umum gambaran hasil penelian ini akan dijabarkan seperti tabel dibawah ini.

Tabel 1. Standar Nilai Persepsi, Nilai Interval, Nilai Interval Konversi, Mutu Pelayanan dan Kinerja Unit Pelayanan

\begin{tabular}{|c|c|c|c|c|}
\hline $\begin{array}{l}\text { Nila } \\
\text { i } \\
\text { Pers } \\
\text { epsi }\end{array}$ & $\begin{array}{c}\text { Nilai } \\
\text { Interval } \\
\text { (NI) }\end{array}$ & $\begin{array}{c}\text { Nilai } \\
\text { Interval } \\
\text { Konver } \\
\text { si (NIK) }\end{array}$ & $\begin{array}{c}\text { Mutu } \\
\text { Pelayana } \\
\text { n (x) }\end{array}$ & $\begin{array}{c}\text { Kinerja } \\
\text { Unit } \\
\text { Pelayana } \\
\text { n (y) } \\
\end{array}$ \\
\hline 1 & $\begin{array}{c}1,00- \\
2,5996\end{array}$ & $\begin{array}{c}25,00- \\
64,99\end{array}$ & $\mathrm{D}$ & $\begin{array}{c}\text { Tidak } \\
\text { baik }\end{array}$ \\
\hline 2 & $\begin{array}{r}2,60- \\
3,064 \\
\end{array}$ & $\begin{array}{c}65,00- \\
76,60 \\
\end{array}$ & $\mathrm{C}$ & $\begin{array}{c}\text { Kurang } \\
\text { baik }\end{array}$ \\
\hline 3 & $\begin{array}{c}3,0644- \\
3,532 \\
\end{array}$ & $\begin{array}{c}76,61- \\
88,30\end{array}$ & B & Baik \\
\hline 4 & $\begin{array}{c}3,5324- \\
4,00\end{array}$ & $\begin{array}{c}88,31- \\
100,00\end{array}$ & A & $\begin{array}{c}\text { Sangat } \\
\text { baik }\end{array}$ \\
\hline
\end{tabular}

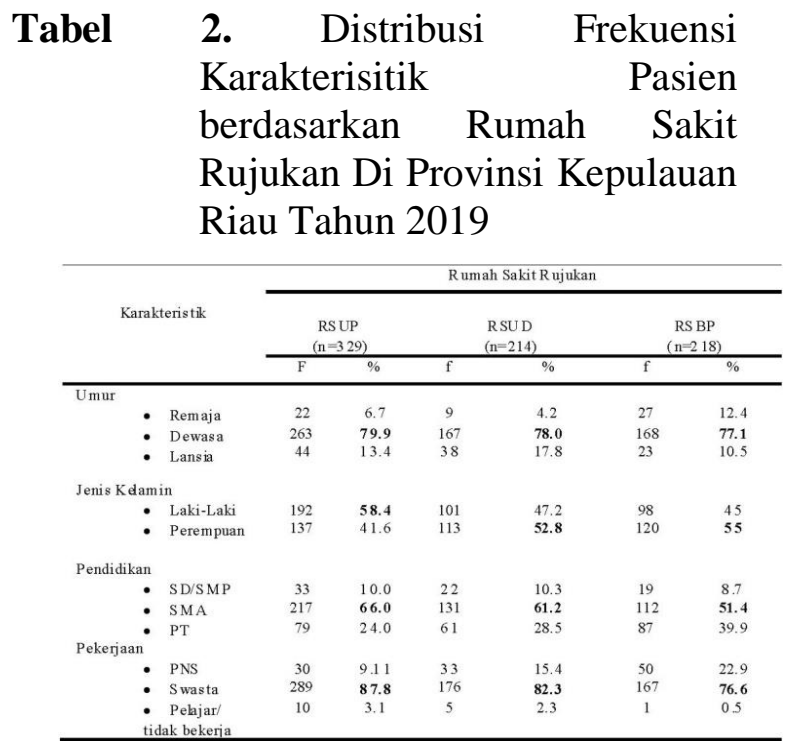

Tabel 2 memperlihatkan pasien di Rumah Sakit rujukan hampir seluruh nya berumur dewasa, khusus untuk RSUP sebagian besar dikunjungi pasien laki laki dengan pendidikan tertinggi SMA dan hampir seluruhnya bekerja di sektor Swasta. 
Tabel 3. Gambaran Kinerja Pelayanan berdasarkan Rumah Sakit Rujukan Di Provinsi Kepulauan Riau Tahun 2019

\begin{tabular}{cccc}
\hline Rumah Sakit & $\begin{array}{c}\text { Nilai Intervel } \\
\text { Konversi } \\
\text { Rata-Rata } \\
\text { Unsur } \\
\text { Pelayanan }\end{array}$ & $\begin{array}{c}\text { Mutu } \\
\text { Pelayanan }\end{array}$ & $\begin{array}{c}\text { Kinerja } \\
\text { Unit } \\
\text { Pelyanan }\end{array}$ \\
\hline RSUP & $\mathbf{7 8 . 0 1}$ & B & Baik \\
RSUD & 76.93 & B & Baik \\
RSBP & 76.03 & C & $\begin{array}{c}\text { Kurang } \\
\text { Baik }\end{array}$ \\
\hline
\end{tabular}

Tabel 3 memperlihatkan kinerja pelayanan RSUP dan RSUD memiliki kinerja baik dibandingkan kinerja RSBP Batam yang kurang baik.

Gambar 1. Gambaran Nilai Indeks Kepuasan Masyarakat berdasarkan Rumah Sakit Rujukan Di Provinsi Kepulauan Riau Tahun 2019

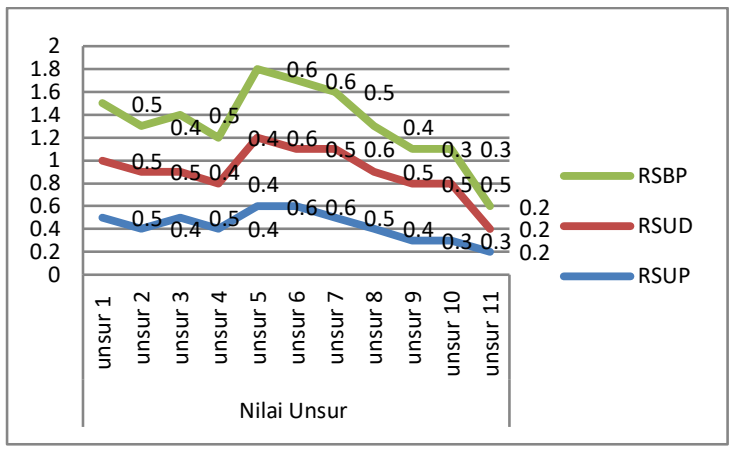

Gambar 1 menunjukkan indeks kepuasaan pasien yang paling tinggi di RSBP, sedangkan RSUP dan RSUP menunjukkan pasien puas terdapat pelayanan.

\section{PEMBAHASAN}

\section{Gambaran Karakteristik Responden}

Karakterisitik Pasien Di Rumah Sakit Rujukan Provinsi Kepulauan Riau hampir seluruhnya berumur dewasa, khusus untuk RSUP sebagian besar dikunjungi pasien laki laki dengan pendidikan tertinggi SMA dan hampir seluruhnya bekerja di sektor Swasta.
Menurut Thornton, D. et (2017) menyatakan bahwa usia merupakan salah satu faktor demografi yang berpengaruh terhadap kepuasan pasien. Semakin dewasa seseorang maka kepuasaan yang dirasakannya semakin objektif karena pada saat seseorang sudah memasuki usia dewasa, cara berpikir seseorang sedang dalam masa baik-baiknya dalam menggunakan logika. Dengan demikan pasien yang dirawat di rumah sakit rujukan di provinsi kepulauan riau hampir seluruhnya berusia dewasa dengan proporsi usia dewasa terbanyak ada pada RSUP (79.9 \%) disusul oleh RSUD (78.0 $\%)$ dan RSBP $(77.7 \%)$.

\section{Gambaran Kinerja Pelayanan di Rumah Sakit Rujukan Di Provinsi Kepulauan Riau.}

Kinerja pelayanan rumah sakit rujukan di Provinsi Kepulauan Riau memperlihatkan kinerja pelayanan RSUP dan RSUD memiliki kinerja baik dibandingkan kinerja RSBP yang kurang baik. Kinerja masing-masing rumah sakit rujukan di Provinsi Kepuluan Riau seperti di RSUP memperlihatkan rerata kinerja baik dengan rata-rata nilai unsur pelayanan 78.01.

Menurut Komisi Akreditasi Rumah Sakit (2018) demi terciptanya pelayanan yang baik di rumah sakit secara keseluruhan baik dari kegiatan klinis maupun manajerial dari setiap ruangan pelayanan, diperlukan kepemimpinan individu yang kompeten. Selanjutnya menurut Triwibowo (2013) apabila pelayanan yang dirasakan melampaui harapan, maka dipersepsikan sebagai pelayanan yang ideal, tetapi apabila pelayanan yang dirasakan lebih rendah dari yang diharapkan maka dapat dipersepsikan kinerja pelayanan buruk. 


\section{Gambaran Nilai Indeks Kepuasan Masyarakat Di Rumah Sakit Rujukan Di Provinsi Kepulauan Riau}

Secara umum mutu layanan yang diberikan oleh rumah sakit rujukan di provinsi kepuluan riau sudah termasuk katagori baik. Dari 11 unsur layanan yang dikaji pada ketiga rumah sakit rujukan di dapat nilai index kepuasan masyarakat yang paling tinggi di RSBP , kemudian diikuti oleh RSUD dan RSUP, dimana menunjukan pasien puas terhadap pelayanan yang di berikan oleh rumah sakit rujukan di provinsi kepuluan riau.

Hasil penelitian ini sama dengan penelitian Rista Ardianti: Wahjoe Pangestoeti, M.Si, (2018) indeks kepuasan masyarakat terhadap pelayanan yang diberikan pada Rumah Sakit Umum Ahmad Tabib Provinsi Kepulauan Riau Tanjung pinang berada pada kategori cukup baik dan Wahdania (2015) menunjukkan bahwa Indeks kepuasan masyarakat terhadap pelayanan Rumah Sakit Umum Daerah (RSUD) Kabupaten Polewali Mandar adalah "Baik" dengan nilai 68,93 begitupun hasil penelitian Nurrizka (2011) di RSUD Achmad Mochtar Sumatera Barat menunjukkan bahwa Indeks kepuasan masyarakat terhadap pelayanan sudah masuk dalam katagori "baik".

Menurut Pohan (2007) mengatakan dalam memberikan pelayanan kesehatan di perlukan pelayanan yang bermutu sehingga pasien merasa puas. Akan tetapi belum terdapat komponen yang bepredikat $\mathrm{A}$ atau sangat bagus di rumah sakit rujukan di Provinsi KEPRI. Kalau dilihat dari Standar Pelayanan Minimal (SPM) di masing masing rumah sakit rujukan. Angka kepuasan masyarakat harus diatas 90\% (Sangat Baik). Oleh karena itu masingmasing rumah sakit rujukan harus melakukan perubahan-perubahan untuk meningkatkan mutu pelayanan kepada masyarakat sebagai pengguna jasa layanan. Nilai kinerja RSBP yang rendah tidak sejalan dengan nilai IKM yang tinggi ini dikarenakan meskipun tidak mempunyai kinerja yang baik, karena RSBP merupakan rujukan terakhir, maka masyarakat hanya mempunyai pilihan rujukan akhir di rumah sakit ini, sehingga IKM terkait dengan tidak ada pilihan lain.

\section{KESIMPULAN}

Hasil penelitian ini menggambarkan kinerja pelayanan RSUP dan RSUD memiliki kinerja baik dibandingkan kinerja RSBP. Indeks kepuasaan pasien di Rumah Sakit Rujukan di Provinsi Kepulauan Riau adalah paling tinggi di RSBP , sedangkan RSUP dan RSUD menunjukkan bahwa pasien memiliki angka kepuasan terhadap pelayanan.

\section{SARAN}

Meningkatkan pelayanan melalui pelayanan prima, peningkatan kompetensi pelaksana, spesifikasi pelayanan dan biaya dan tarif. Adanya informasi biaya dan tarif yang yang dipublikasikan serta peningkatan kompetensi pelaksana/ petugas yang ada di rumah sakit. Baik perawat, dokter, dan tenaga kesehatan lainnya.

\section{UCAPAN TERIMA KASIH}

Terima kasih penulis ucapkan kepada seluruh responden yang terlibat dalam penelitian ini, dan pihak-pihak terkait sehingga hasil penelitian dapat dipublikasikan.

\section{DAFTAR PUSTAKA}

Dwiyanto, A. (2003). Reformasi Tata Pemerintahan dan Otonomi Daerah. Pusat Studi Kependudukan Dan KeBijakan, Universitas Gadjah Mada, Yogyakarta.

Handayani, S. (2016). Tingkat Kepuasan 
NERS: Jurnal Keperawatan,Volume 15, No. 2, Oktober 2019, (Hal. 119-124)

Pasien Terhadap Pelayanan Kesehatan

Di Puskesmas Baturetno. Profesi (Profesional Islam) : Media Publikasi Penelitian, 14(1), 42. Https://Doi.Org/10.26576/Profesi.135

Komisi Akreditasi Rumah Sakit. (2018). Standar Nasional Akreditasi Rumah Sakit (Snars Ed.1) (Edisi 1). Jakarta: Kerjasama Direktorat Jenderal Bina Upaya Kesehatan, Kementerian Kesehatan Republik Indonesia Dengan Komisi Akreditasi Rumah Sakit (Kars).

Kotler, P. Dan K. L. K. (2008). Manajemen Pemasaran (Jilid I). Jakarta: Penerbit Erlangga.

Latupono, A., M. M. Alimin ., Dan A. Z. (2015). Hubungan Mutu Pelayanan Terhadap Kepuasan Pasien Rawat Inap Di Rsud Masohi. Jst Kesehatan, 5,1 .

Ndambuki, J. (2013). The Level Of Patients' Satisfaction And Perception On Quality Of Nursing Services In The Renal Unit, Kenyatta National Hospital Nairobi, Kenya From Patient Satisfaction. Open Journal Of Nursing, 3, 186-194.

Nurrizka, R. H. (2011). Pengukuran Indeks Kepuasan Masyarakat Terhadap Pelayanan Kesehatan. Jurnal Manajemen Pelayanan Kesehatan, 14, 01.

Pohan, I. (2007). Jaminan Mutu Layanan Kesehatan: Dasar-Dasar Pengertian Dan Penerapan. Jakarta: EGC.

Ardianti, R, \& Pangestoeti, W. (2018). Indeks Kepuasan Masyarakat Di Rumah Sakit Umum Daerah (Rsud)
Raja Ahmad Tabib Provinsi Kepulauan Riau. Universitas Maritim Raja Ali Haji, 1-20.

Singh, S., Kaur, P., \& Rochwani, R. (2013). Patient Satisfaction Levels In Atertiary Care Medical College Hospital In Punjab, North India. Community Medicine, I(November), 172-182.

Thornton, D. Et, A. (2017). Influence On Patient Satisfaction In Healthcare Centers: A Semi Quantitative Study Over 5 Years. Bmc Healthserv, 17, 19.

Triwibowo. (2013). Manajemen Pelayanan Keperawatan Di Rumah Sakit. Jakarta: Tim.

UUD. (1945). Undang-Undang Dasar Negara Republik Indonesia Tahun 1945. Ecosystems And Human WellBeing: A Framework For Assessment, 12(16), 81-87. Https://Doi.Org/10.1007/S13398-0140173-7.2

Wahdania1, Djuliati Saleh, F. (2015). Indeks Kepuasan Pasien Terhadap Pelayanan Rumah Sakit Umum Daerah (Rsud) Kabupaten Polewali Mandar. Jurnal Administrasi Publik, Nomorl.

World Competitiveness Ranking. (2018). T H E 2018 I M D Wo R L D. World Competitiveness Ranking, 162(20), 99-100. 